\title{
Changing Demographic Profile of the Spinal Cord Injury Population: Implications for Health Care Support Systems
}

\author{
Myron G. Eisenberg, Ph.D. ${ }^{1}$ and Diana O. Tierney, Ph.D. ${ }^{2}$ \\ ${ }^{1}$ Chief, ${ }^{2}$ Consultant, Psychology Service, Veterans Administration Medical Center, \\ Hampton, Virginia. ${ }^{1}$ Associate Professor, Assistant Research Professor, Departments \\ of Mental Health and Behavioral Science, and Physical Medicine and Rehabilitation, \\ Eastern Virginia Medical School, Norfolk, Virginia, U.S.A.
}

\begin{abstract}
Summary
Currently, the majority of Spinal Cord Injury (SCI) treatment resources are being expended to address and resolve problems occurring during the acute and immediate post-acute phases following injury. Major national funding sources for SCI research have followed this pattern with few, if any, proposals submitted for the support of research into the effects of aging on the SCI individual requiring long term institutional care. Yet, data recently available from the National Spinal Cord Injury Research Center and the Veterans Administration show that there is an increase in the numbers of older SCI persons requiring medical care. In anticipation of increasing utilisation of health care resources by older SCI persons, the Veterans Administration has begun to make appropriate plans. But a broadened information base is needed to support these plans. Statistical data concerning the characteristics of the total SCI population, empirical information of older SCI persons' extended care needs, and information regarding proper treatment for older SCI persons is necessary.
\end{abstract}

Key words: Spinal cord injury; Demographics; Health care; Geriatrics.

\section{Introduction}

Realistic concern for the needs of the ageing or institutionalised spinal cord injured population will stimulate development of future goals for modern SCI treatment. To date most researches in this field has been focussed on the aetiology of SCIs and the acute care and rehabilitation of SCI persons (e.g., Eisenberg and Falconer, 1978; Guttmann, 1978; Thomas, 1984). Consistent with this emphasis on acute care, 17 of the 19 SCI centres established within the Veterans Administration's national health care network in the U.S.A. have been designated to provide acute and intermediate care for SCI veterans. The National Institute of Handicapped Research (NIHR) and the National Institute of Neurological and Communicative Disorders and Stroke (NINCDS) funded SCI centres developed within the civilian sector, also provide EMS/acute care. Several major national funding sources financing SCI research (e.g., the 
Rehabilitation Services Administration, the National Institute for Handicapped Research, and the Paralyzed Veterans of America Spinal Cord Research Foundation) have also followed this pattern with few, if any, proposals submitted for the funding of researches concerning the effects of ageing and/or institutionalisation on the SCI individual (Thomas, 1984).

As greater numbers of spinal cord injured individuals are surviving the injury for extended periods, psychosocial and medical problems associated with the ageing process will undoubtedly have an impact on health care systems. While the average life span of SCI persons may not yet be equal to that of the ablebodied population (DeVivo et al., 1984; Young et al., 1982), in recent years the SCI persons' life expectancies have significantly lengthened and now approach that of the general public (Mesard et al., 1978). Thus, as health care providers prepare to meet the increasing need for geriatric care among the overall population, it will also be important to consider the unique implications which ageing and extended institutionalisation may have for the SCI person. Prompt attention to this issue is needed to predict and to prepare for the physical and financial implications. Unfortunately, there is currently little information available in the literature upon which health care planners may base their decisions about the long term treatment and residential care needs of this growing segment of the SCI population.

\section{Changing profile of the SCI population}

Until the mid-1940s there was little opportunity to provide extended care for SCI patients because the majority of spinal cord injured persons failed to survive the initial trauma or died soon afterwards, usually as a result of infection (Guttmann, 1978). Today, after two decades of rapid scientific advances including the discovery of broad spectrum antibiotics and other pharmacological agents, the development of new surgical techniques, the improvements in rehabilitation, and attention to the psychosocial problems created and/or exacerbated by the disability, the life expectancy of the spinal cord injured patient has been significantly extended (Eisenberg and Falconer, 1978; Guttmann, 1978; Howell, 1978; Messard et al., 1978). The longer life expectancy of these patients coupled with a trend towards a longer life expectancy for the 'general population may be reflected in a changing demographic profile of SCI persons seeking medical care.

While definitive information regarding the characteristics of SCI persons who have historically utilized the full spectrum of health care services is not available, two relatively new data sources provide suggestive evidence of an upward trend in the numbers of older SCI persons seeking medical care. The first, the National Spinal Cord Injury Data Statistical Center, is located at the University of Alabama at Birmingham's Spain Rehabilitation Center. The Statistical Center compiles information received from 17 NIHR funded SCI centers and, building on the data base initiated by the National Spinal Cord Data Reseatch Center, has accumulated data on approximately 8500 cases admitted to these centres since 1973. The second data source, the Veterans Administration (VA), has compiled information on over 18,000 SCI veterans discharged from VA Medical Centers or VA SCI centres since 1975. Prior to the first statistical report on SCI veterans 


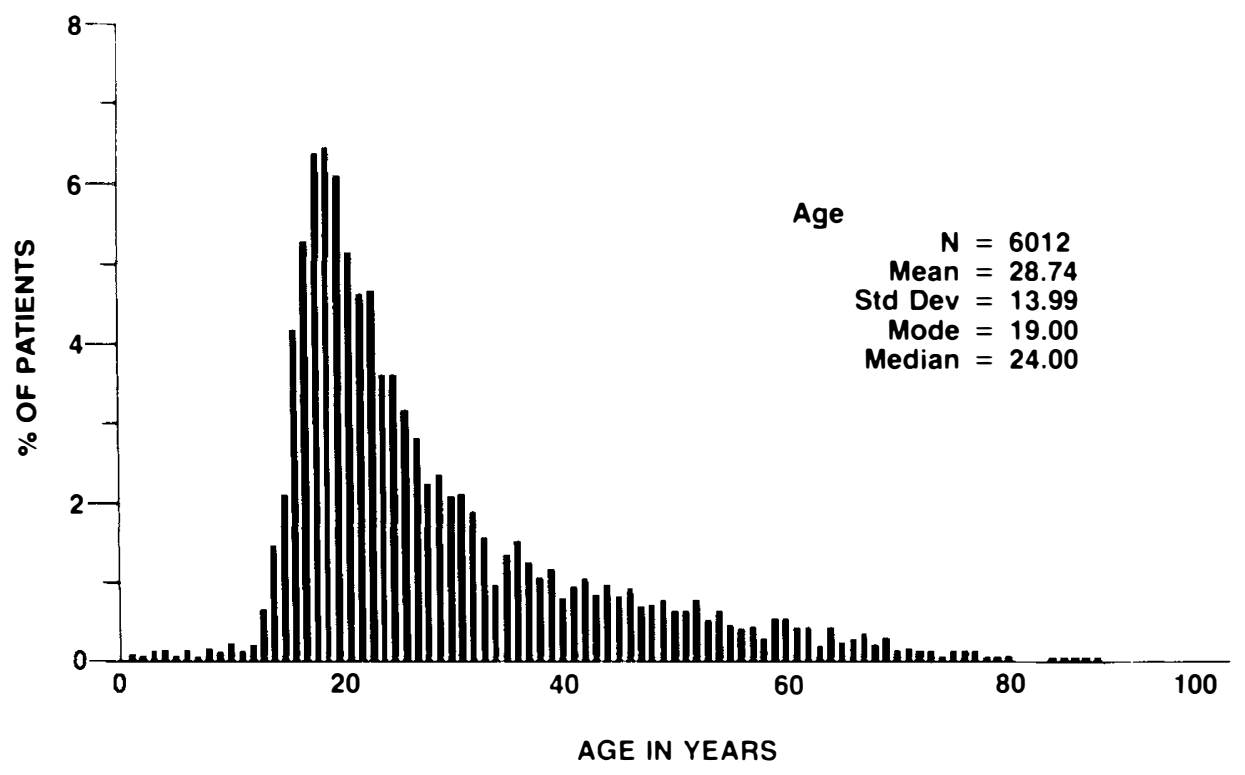

Figure 1.

discharged from VA facilities, covering the FY76-FY81 time period, information regarding the large group of SCI veterans could primarily be obtained through surveys of patient records. Today, plans call for the VA to issue statistical reports regarding all SCI veterans discharged on an annual basis.

By primarily drawing upon the statistical information available from these two sources, several tentative statements can be made about the changing parameters of the SCI patient population. First, the available data provides further evidence of a well established feature of SCIs; that these injuries usually tend to occur in the 19-34 age group. Data presenting the demographic characteristics of a sample of SCI patients first treated for trauma to the spinal cord in a VA hospital between October, 1955 and September, $1965(\mathrm{~N}=2323)$ indicates that approximately 70 per cent were between the ages of 17 and 35 at the time of their injury. Of this group, 87 per cent had been admitted to the VA within one year of their injury (Mesard et al., 1978). Similar data reported from the National Spinal Cord Injury Statistical Center indicates that for patients treated/rehabilitated at NIHR funded centres prior to $1982(\mathrm{~N}=6012)$ the median age at injury was 24 years (Fig. 1). In the past, the majority of VA and private sector treatment resources have been expended for the immediate care and rehabilitation of this relatively young and acutely injured SCI patient group.

Second, given the established fact that the majority of SCIs occur before age 35, it would appear that the longer term care needs of middle to older aged SCI veterans are already beginning to have an impact on the VA health care system. Recent data provided by the SCI Service, VA Central Office, indicates that approximately 60 per cent of the SCI veterans discharged from 


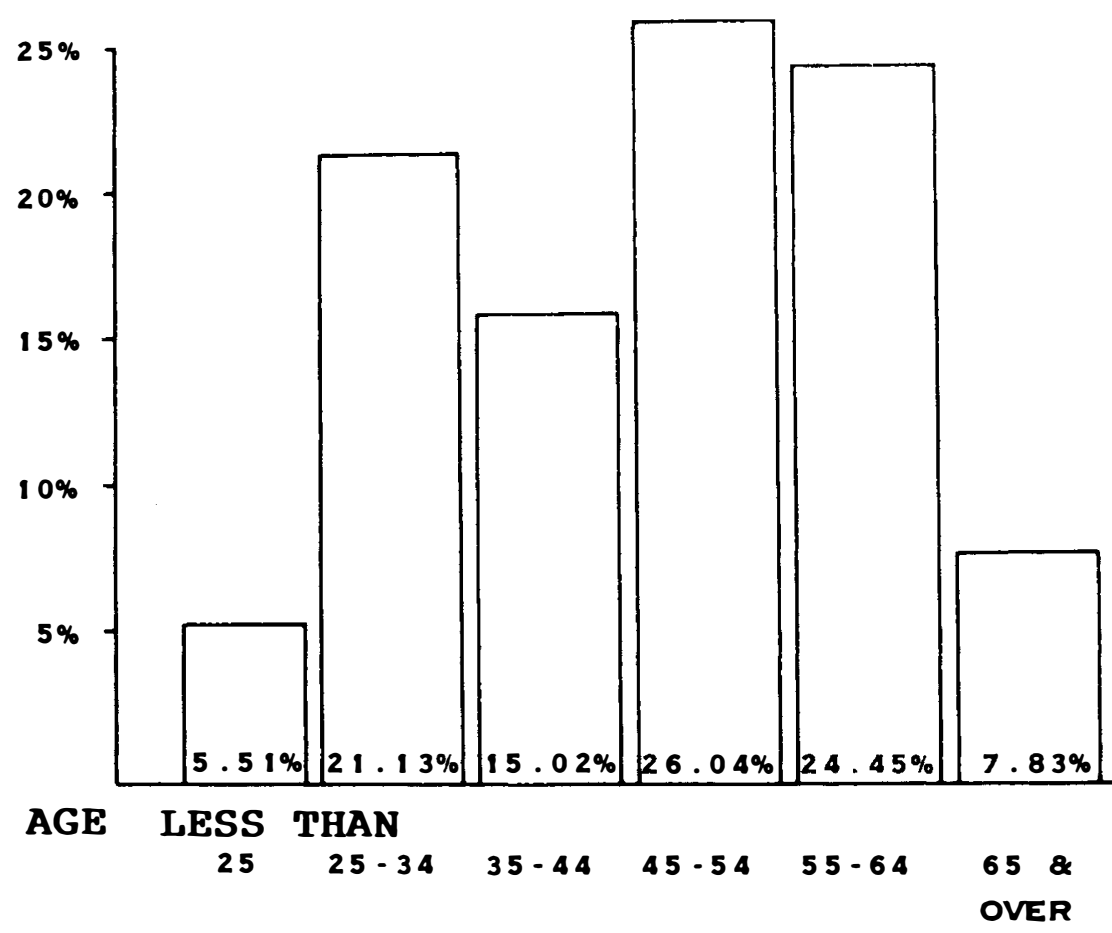

Figure 2.

VAs nationwide between 1976 and 1981 (over 69,000 discharges) were 45 years of age or older (Fig. 2). Comparable data for the civilian sector is not yet available. However, the National Spinal Cord Injury Statistical Center has compiled information which suggests the incidence of selected medical complications which may require rehospitalisation of SCI persons in the early years following injury (Table 1).

Finally, the available data suggest that in the near future other salient factors, in addition to medical complications, may result in increased or changing care requirements for a large segment of the SCI population. Today, following their initial hospitalisation for stabilisation and rehabilitation, individuals with SCIs generally return to a community support network which may include a spouse (often approximately the same age as his/her disabled partner); parents (often middle aged or older); or extended family members representing the young or middle aged groups. For the 1976-1981 time interval approximately 85 per cent of the SCI veterans discharged from VA Medical Centers returned to the community (Table 2). Discharge data from the National Spinal Cord Injury Statistical Center are similar, with approximately 92 per cent of civilians treated in the 125 U.S. medical and rehabilitation hospitals being surveyed in 1976 discharged directly to their homes (Young et al., 1982) (Table 3).

However, as spinal cord injured individuals continue to survive for longer 
Table 1. Annual incidence of selected medical complications in years following injury

\begin{tabular}{llr}
\hline Medical complication & \multicolumn{1}{c}{ Diagnostic codes } & Inc. $^{\star}\left({ }^{\circ}{ }_{0}\right)$ \\
\hline Urinary & $580 \cdot 0-584 \cdot 0,590 \cdot 0-599 \cdot 9,789 \cdot 1,789 \cdot 3$ & $65 \cdot 3$ \\
Spasms & $780 \cdot 3$ & $19 \cdot 1$ \\
Pain & $728 \cdot 0-728 \cdot 9,783 \cdot 7,785 \cdot 5,786 \cdot 0,787 \cdot 1,787 \cdot 3$ & $7 \cdot 8$ \\
Pulmonary & $450 \cdot 0,465 \cdot 0,466 \cdot 0,471 \cdot 0,480 \cdot 0-486 \cdot 0$, & $13 \cdot 3$ \\
& $490 \cdot 0-493 \cdot 0,510 \cdot 0-519 \cdot 9,796 \cdot 0$ & \\
Neuroses & $300 \cdot 0-301 \cdot 9,303 \cdot 0-304 \cdot 9,307 \cdot 0$ & $4 \cdot 2$ \\
Pressure sores & $707 \cdot 0$ & $22 \cdot 9$ \\
Ossification & $733 \cdot 2,733 \cdot 9$ & $6 \cdot 0$ \\
Dysreflexia & $358 \cdot 9$ & $6 \cdot 0$ \\
Burns & $940 \cdot 0-949 \cdot 9$ & $2 \cdot 0$ \\
Curvature & $735 \cdot 0-735 \cdot 2,735 \cdot 9$ & $3 \cdot 7$ \\
Fractures & $812 \cdot 0-813 \cdot 9,818 \cdot 0-824 \cdot 9,729 \cdot 0,729 \cdot 9$ & $3 \cdot 6$ \\
Septicemia & $038 \cdot 0-038 \cdot 2,038 \cdot 9$ & $2 \cdot 7$ \\
Obesity & $277 \cdot 0$ & $2 \cdot 1$ \\
Anemia & $280 \cdot 0-285 \cdot 9$ & $2 \cdot 4$ \\
Phlebitis & $451 \cdot 0,451 \cdot 9$ & $1 \cdot 9$ \\
\hline
\end{tabular}

*Incidence

Table 2. Places of discharge for all SCI veterans

\begin{tabular}{lrr}
\hline & $\mathrm{N}$ & Percent \\
\hline 1. Return to Community & 54,949 & $84 \cdot 53$ \\
2. VA Hospital & 5,249 & $8 \cdot 07$ \\
3. Community Nursing Home & 2,230 & $3 \cdot 43$ \\
4. SCI HCU Programme & 1,157 & $1 \cdot 78$ \\
5. VA Nursing Home & 854 & $1 \cdot 31$ \\
6. HBHC Programme & 204 & $0 \cdot 31$ \\
7. VA Domiciliary & 122 & $0 \cdot 19$ \\
8. Other & 65 & $0 \cdot 10$ \\
9. Community Hospital & 42 & $0 \cdot 07$ \\
10. Unknown & 36 & $0 \cdot 06$ \\
11. Other Government Hospital & 21 & $0 \cdot 03$ \\
12. Foster Home & 21 & $0 \cdot 03$ \\
13. State Care & 20 & $0 \cdot 03$ \\
14. State Home Domiciliary & 20 & $0 \cdot 03$ \\
15. Military Hospital & 10 & $0 \cdot 02$ \\
16. Halfway House & 3 & $0 \cdot 01$ \\
17. Other Federal Hospital & 2 & $0 \cdot 003$ \\
18. Residential Care & 2 & $0 \cdot 003$ \\
19. Boarding House & 1 & $0 \cdot 002$ \\
Totals & 65,008 & $100 \cdot 00^{\circ}{ }_{0}$ \\
\hline
\end{tabular}

Table 3. Residence following discharge from 125 US Medical-Rehabilitation Hospitals

\begin{tabular}{cccc}
\hline \multirow{2}{*}{$\begin{array}{c}\text { Number of } \\
\text { cases }\end{array}$} & \multicolumn{3}{c}{ Residence on discharge } \\
\cline { 2 - 4 } N & Home & $\begin{array}{c}\text { Nursing } \\
\text { Home }\end{array}$ & Other \\
\hline 325 & ") & & \\
283 & 96 & 3 & 1 \\
206 & 92 & 7 & 1 \\
\hline
\end{tabular}


periods of time their primary care providers are also ageing and may become less capable of providing for the considerable physical care needs necessary to maintain the injured person's well being. As these anticipated changes occur in the current support network for SCI persons, health care institutions may more frequently be called upon to develop additional extended care resources to assume major or total responsibility for the care of spinal cord injured persons.

\section{Future directions}

In anticipation of an increasing health care services utilisation rate by older SCI persons, the VA is currently engaged in planning for the systematic expansion of programmes targeted at the ageing SCI veteran population. At present, there are two long term care units established by the VA, a 64 bed unit at Hampton, Virginia, and a 58 bed unit at Brockton, Massachusetts, accounting for 122 $(11 \cdot 1 \%)$ of the 1354 VA Medical Center beds currently available to SCI veterans requiring short or long term care. By the mid 1990s the VA hopes to establish seven additional SCI centres and designate approximately 394 (or $24 \%$ ) of the anticipated 1644 beds available at that time as long term care beds-an increase in designated long term care beds of 13 per cent above the current level. In addition, the VA has recently indicated that four out of every 60 new VA nursing home beds (which numbered 9420 effective FY 1983) will be made available as needed to accommodate SCI veterans requiring long term care. VA preparation for the anticipated influx of SCI patients requiring long term care also includes the consideration of staffing criteria tailored to the treatment requirements of long term SCI veterans; SCI home care programmes which assist patients to live in the community; and the current development of a Registry of SCI veterans. Plans call for the Registry to be implemented by 1986 (Sheldon, 1984).

Relative to the VA, less attention has thus far been paid in the U.S.A. by the civilian health care sector to planning for the anticipated increase in ageing civilian spinal cord injured persons. Currently, civilian SCI persons who require long term custodial care must seek it from nursing homes which by and large do not specialize in SCI care and may or may not employ staff with specific expertise in the care of the spinal cord injured. The National Spinal Cord Injury Association, the largest consumer advocacy organisation representing the civilian cord injured population, as yet has not considered the need to lobby for the creation of additional community-based long term care beds suitable to accommodate aging SCI persons. However, this and other steps may be taken as the civilian health care sector recognises the need to gradually expand its structural capacity to respond fully to the needs of the ageing SCI person.

The further development and dissemination of basic statistical and evaluative information regarding SCIs and care in the ageing is needed to support the planned and anticipated growth in long term SCI services provided by the VA and the civilian sector respectively. First, in order to provide the most efficacious treatment for older SCI persons, practitioners must become thoroughly acquainted with the longer term, as well as short term, psychological and physiological consequences of SCI. A wealth of information exists regarding the immediate problems following the injury as well as the multidisciplinary 
interventions required to assist the SCI person to gradually adapt to his/her changed physical and psychosocial status. In recent years the number of published scholarly papers on SCI topics has greatly increased and the focus of research and theorising in this field has shifted from the treatment of medical complications, to attitudinal adjustment and enrichment of life following injury (Young, Burns et al., 1982). A review of the literature, however, reveals a paucity of data documenting the incidence and intensity of problems encountered by the post-rehabilitated, ageing SCI person. Also noteworthy is the lack of research examining the effects of institutional life on SCI patients and their treatment needs.

Those pertinent reports which were identified in our review of the literature raise questions which further underscore the necessity for indepth investigation of these topics. For example, a recent paper has speculated regarding premature symptoms of ageing (e.g., decreased resistance to infection, premature hypertension and arteriosclerotic cardiovascular disease) in SCI patients (Ohry et al., 1983). A second recent paper presents evidence suggesting a positive relationship between the psychological well-being of middle aged and elderly community residing SCI persons and self-perceived levels of control over their lives, perceived level of social support, and positive judgments of their overall health status (Decker, 1983). These reports touch upon issues regarding the health and psychological status of SCI patients which may have significant implications for the planning of SCI custodial programming. Additional research, and the timely dissemination of information to SCI practitioners, is needed on these topics as well as the following:

1. Nature of medical, psychological and social problems typically encountered by older and/or institutionalised, post-acute SCI persons.

2. Self-perceived care needs of ageing and/or institutionalised post-acute SCI persons.

3. Guidelines for the development of cost-effective and therapeutically efficacious programme elements appropriate for long-term residential care SCI facilities.

4. Areas of didactic and experiential training in geriatric issues needed by health care practitioners working with spinal cord injured persons.

Second, there is a need for additional, basic statistical information regarding the demographic characteristics of the SCI population, the incidence of medical and psychosocial problems among SCI persons across developmental stages and the projected number of SCI persons who will require custodial care in the foreseeable future. The development of an SCI registry by the VA is an important step towards filling this need and, once operational, should enable the VA to modify and target treatment resources in accordance with changing care needs of the SCI veteran population. Plans call for the Registry information for each SCI veteran to include at least the following variables: date, cause and level of injury; address, ethnicity and pre-injury employment status; nature of hospital visit (admission or follow-up); reason for admission; extent of neurological deficits; and length of stay.

Additional on-going planning by the VA and the Spinal Cord Injury Statistical Center may ultimately remove another current limitation of the available statistical information on SCI patients; that is, the lack of comparability between the 
statistical information compiled by the VA and the Spinal Cord Injury Statistical Center. Discussion of this issue by the two agencies is in the early stages but hopefully will result in the compilation of compatible information and a more complete picture of the extent and nature of SCI extended care needs (Copperthite, 1985). Aggregate statistics concerning the characteristics of the total SCI population, treatment received and projected programming needs will facilitate the efforts of both agencies to develop long term health care goals and establish service and research priorities.

In summary, our review of the literature suggests the need for additional empirical information to support the service planning and care delivery efforts of SCI programme administrators and practitioners alike. Because of the increasingly large number of ageing SCI persons, prompt investigation of these issues is needed to ensure that this segment of the SCI population will be able to secure competent and compassionate care with specific attention to the needs encountered with advancing age.

\section{Résumé}

A présent la plupart des ressources pour le traitement des blessures des cordons spinaux (paraplégies et quadraplégies) sout dépensées pour étudier et résourdre des phases aigues et les phases aigues et les phases qui suivent. Les fonds principaux aux Etats-Unis qui soutiennent cette recherche spinale out suivi ce même chemin, avec très peu de propositions de recherches suggérées pour etudier des conséquences des paralysies chroniques sur le processus de vieillissement pour ceux qui doivent rester long temps dans les institutions médicales. Pourtant, des renseignements démographiques sur ce sujet donnés par le National Spinal Cord Injury Research Center et le Veterans Administration (l'Organisation des Ancients Combattants) montrent que le nombre de paralysées chroniques âgés augmentent, et ces malades ont besoin d'aide médicale.

Avec l'augmentation anticipée de l'utilisation des ressources médicales par les paralysés chroniques et âgés, le Veterans Administration a commencé à tracer des projets pour agrandir systématiquement ces programmes des anciens combattants avec des paralysies chroniques. Cependent, une base d'information nouvelle doit être développée pour soutenir des efforts coursants et pour avance les programmes de l'avenir pour ceux qui organisent, aussi bien que ceux qui traitent ces gens paralysés. les renseignements critiques recherchés comprehnnent les statistiques démographiques de la population paralysée, des observations empiriques qui concernent la nature des besoins à longue haleine des paraplégiques et quadriplégiques âgés, et des évaluations à propos du traitement efficace des paralysés âgés.

\section{Zusammenfassung}

Momentan, die Mehrheiten die SCI (Wirbelsäule Verletzung) Behandlung Hilfsquellen sind aufwendet zu adressieren und entscheiden die Problemen. Die während akut und sofort nach-akute Phasen gefolgte Verletzung. Grössere National Stipendiumen für SCI Forschung hatte gefolgt diese Modell mit wenige, fals einige, Verschläge fügten nicht für die Unterstützung der Forschung welcher untersuchen werden wird die Leistungen der Älteren an der SCI Individual, Die verlangen Langseitinstitutional Fürsorge. Sogar, Daten, Die nicht lange sind nur verfügbar von der National Spinal Cord Injury Research Center und Veterans Administration geben andeutende Klarheit für eine aufwärts Neigung in den Zahlen der älterer SCI Personen Die Medizinische Pflege verlangen. Mit Erwartung an grössere Utilisierung der Krankheit Verteidigung Findigkeit beim älter SCI Personen der Veterans Administration Wurde angefangen zu planen für die systematische Ausdähnung der Programmen für die ältere SCI Veteran Bevölkerung. Aber, weitere Unterweisung Basis muss man haben zu unterstützen diese und weitere SCI Dienst Entwicklung und Entbindung Bemühung mit SCI Program Konstrukturen und Praktikanten. Kritische Unterweisung man soll statistische entschliessende Daten haben hinsichtlich karakteristisch die total SCI Bevölkerung, empirische Unterweisung, betreffend die Natur der ältere SCI Bevölkerung, erweiterende Fürsorge, und hinsichtlich auswärtige Unterweisung, gerämmiges Behandlung Elemente für ältere SCI Personen. 


\section{Acknowledgements}

Appreciation is extended to Dr Michael Devivo, Manager, Analytic Services, National Spinal Cord Statistical Center, and Ms Joan Sheldon, Chief, Psychosocial Rehabilitation, SCI Service, VA Central Office, for their thoughtful critiques of earlier drafts of this paper. Thanks also to Dr John Young, Good Samaritan Medical Center, for graciously permitting the use of data obtained through the Regional Spinal Cord Injury Systems.

\section{References}

Copperthite A Administrative Assistant, Veterans Administration Central Office, Washington, DC, Personal communication. January 25, 1985.

DECKER SD 1983 Sociai support and well-being in middle-aged and elderly spinal cord injured persons: A social psychological analysis. Dissertations Abstract International 43(10-B):3407.

DeVivo MJ, Fine PR, STover SL March 26-28, 1984 Seven year survival following spinal cord injury. In: American Spinal Injury Association's Tenth Annual Scientific Meeting Abstracts Digest: 71-76.

EISENBERG MG, Falconer J (eds) 1978 Treatment of the Spinal Cord Injured. Springfield, Charles C. Thomas.

Guttmann L 1978 Spinal Cord Injuries: Comprehensive Management and Research. London, Blackwell Scientific Publications.

Howell L 1978 Spinal cord injury. In Goldenson RM, Dunham JR, Dunham CS, Disability and Rehabilitation Handbook. New York, McGraw-Hill.

Mesard L, Carmody A, Mannarino E, Ruge D 1978 Survival after spinal cord trauma. A life table analysis. Archives of Neurology 35:78-83.

OHRy A, Shemesh Y, Rozin R 1983 Are chronic spinal cord injured patients prone to premature aging? Medical Hypotheses 11(4):467-469.

Sheldon J Chief, Psychological Rehabilitation, Spinal Cord Injury Service, Veterans Administration Central Office Washington, DC, Personal communication. August 6, 1984.

Thomas JP Director Medical Research Unit, National Institute of Handicapped Research, Washington, DC, Personal communication. August 14, 1984. 